\title{
Minimizing scattering from antireflective surfaces replicated from low-aspect-ratio
} black silicon

\author{
Christiansen, Alexander Bruun; Clausen, Jeppe; Mortensen, N. Asger; Kristensen, Anders
}

Published in:

Applied Physics Letters

Link to article, DOI:

$10.1063 / 1.4754691$

Publication date:

2012

Document Version

Publisher's PDF, also known as Version of record

Link back to DTU Orbit

Citation (APA):

Christiansen, A. B., Clausen, J., Mortensen, N. A., \& Kristensen, A. (2012). Minimizing scattering from

antireflective surfaces replicated from low-aspect-ratio black silicon. Applied Physics Letters, 101(13), 131902. https://doi.org/10.1063/1.4754691

\section{General rights}

Copyright and moral rights for the publications made accessible in the public portal are retained by the authors and/or other copyright owners and it is a condition of accessing publications that users recognise and abide by the legal requirements associated with these rights.

- Users may download and print one copy of any publication from the public portal for the purpose of private study or research.

- You may not further distribute the material or use it for any profit-making activity or commercial gain

- You may freely distribute the URL identifying the publication in the public portal 


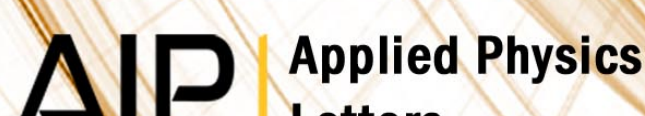 Letters}

\section{Minimizing scattering from antireflective surfaces replicated from low- aspect-ratio black silicon}

Alexander B. Christiansen, Jeppe Clausen, N. Asger Mortensen, and Anders Kristensen

Citation: Appl. Phys. Lett. 101, 131902 (2012); doi: 10.1063/1.4754691

View online: http://dx.doi.org/10.1063/1.4754691

View Table of Contents: http://apl.aip.org/resource/1/APPLAB/v101/i13

Published by the American Institute of Physics.

\section{Related Articles}

Stress evaluation in thin strained-Si film by polarized Raman spectroscopy using localized surface plasmon resonance

Appl. Phys. Lett. 101, 172101 (2012)

Statistical theory and applications of lock-in carrierographic image pixel brightness dependence on multicrystalline Si solar cell efficiency and photovoltage

J. Appl. Phys. 112, 054505 (2012)

Signal contrast in coherent Raman scattering: Optical phonons versus biomolecules

J. Appl. Phys. 112, 053101 (2012)

Indirect optical absorption in silicon via thin-film surface plasmon

J. Appl. Phys. 112, 043103 (2012)

Strong photoluminescence from diameter-modulated single-walled carbon nanotubes

Appl. Phys. Lett. 101, 043123 (2012)

\section{Additional information on Appl. Phys. Lett.}

Journal Homepage: http://apl.aip.org/

Journal Information: http://apl.aip.org/about/about_the_journal

Top downloads: http://apl.aip.org/features/most_downloaded

Information for Authors: http://apl.aip.org/authors

\section{ADVERTISEMENT}
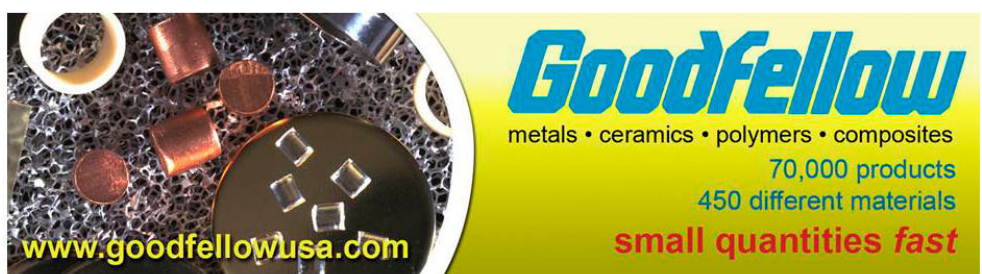


\title{
Minimizing scattering from antireflective surfaces replicated from low-aspect-ratio black silicon
}

\author{
Alexander B. Christiansen, ${ }^{1}$ Jeppe Clausen, ${ }^{2}$ N. Asger Mortensen, ${ }^{2}$ \\ and Anders Kristensen ${ }^{1, a)}$ \\ ${ }^{1}$ Department of Micro and Nanotechnology, Technical University of Denmark, Oersteds Plads, Building 345B, \\ DK-2800 Kgs. Lyngby, Denmark \\ ${ }^{2}$ Department of Photonics Engineering, Technical University of Denmark, Oersteds Plads, Building 343, \\ DK-2800 Kgs. Lyngby, Denmark
}

(Received 2 July 2012; accepted 11 September 2012; published online 24 September 2012)

\begin{abstract}
The scattering properties of randomly structured antireflective black silicon polymer replica have been investigated. Using a two-step casting process, the structures can be replicated in Ormocomp on areas of up to $3 \mathrm{in}$. in diameter. Fourier analysis of scanning electron microscopy images of the structures shows that the scattering properties of the surfaces are related to the spatial periods of the nanostructures. Structures with a dominating spatial period of $160 \mathrm{~nm}$, a height of $200 \mathrm{~nm}$, and aspect ratio of 1.3 show insignificant scattering of light with wavelength above $500 \mathrm{~nm}$ and lower the reflectance by a factor of two. (C) 2012 American Institute of Physics.

[http://dx.doi.org/10.1063/1.4754691]
\end{abstract}

Antireflective nanostructures have the potential to provide an alternative to expensive coatings for optical components. High aspect ratio structures with periods around $200 \mathrm{~nm}$ have been shown to greatly reduce Fresnel reflections for a broad band of wavelengths. ${ }^{1}$ Such periodic structures can be fabricated on large areas by laser interference lithography $^{2}$ or by anodized aluminium oxide. ${ }^{3}$ An important feature of this kind of structure is that below a certain ratio between period and wavelength, only zeroth order diffraction will occur at the surface, and no light will be scattered. ${ }^{4,5}$ Minimizing scattering is crucial when the antireflective element is to remain fully transparent and increase the direct transmission of light. Only recently, the scattering properties due to imperfections in periodic structures have been studied. ${ }^{6}$

Another method for fabricating antireflective surfaces is by pattern transferral of the nanostructures in black silicon (BSi) surfaces. BSi structures are randomly positioned, coneshaped formations, formed in silicon by a mask-less etching process. ${ }^{7}$ However, due to the random nature of these structures, such surfaces will inherently scatter incoming light. Several studies have used this type of structures for antireflection, ${ }^{8-10}$ but the scattering properties of the surfaces have only recently been addressed. ${ }^{11}$

In this letter, we present a simple method for replicating BSi structures into Ormocomp, a transparent organicinorganic hybrid polymer (Micro resist technology Gmbh, Berlin), on areas of up to $3 \mathrm{in}$. in diameter. The silicon masters were characterized by scanning electron microscopy (SEM) and dark field microscopy, and the Ormocomp replica were characterized by SEM and Fourier analysis, and light transmission measurements. The structures which showed increased transmission for light with a wavelength down to $500 \mathrm{~nm}$ were used to demonstrate the antireflective effect, which was significant even for structures with aspect ratio as low as 1.3.

\footnotetext{
a)Electronic mail: anders.kristensen@nanotech.dtu.dk.
}

The BSi substrates were structured by reactive ion etching (Pegasus DRIE, STS). The structures were formed in a single etching cycle with an $\mathrm{O}_{2} / \mathrm{SF}_{6}$-based etch. ${ }^{7}$ By varying the gas-flows and platen power, different types of $\mathrm{BSi}$ surfaces were fabricated, denoted from hereon as types A-F.

After etching the BSi substrates [See Fig. 1(a1)], the surface can be patterned using conventional photolithography and dry etching to remove the nanostructures from the defined areas (a2). Using molecular vapor deposition, the BSi masters were coated with an anti-stiction layer. Ormocomp was poured on the master (a3) and a $1.5 \mathrm{~mm}$ thick and 4 in. wide polymethylmethacrylate (PMMA) substrate was placed on top. The thickness of the Ormocomp film was controlled by placing spacers at the periphery, between the master and PMMA back plate. The Ormocomp was cured with UV light in the wavelength range of $260-320 \mathrm{~nm}$, through the PMMA (a4). The type of PMMA is Plexiglas XT 20070, which has a limited but sufficient transmittance in the 260-320 nm range. After UV exposure, the flexibility of the Ormocomp and PMMA allowed for the gradual releasing of the Ormocomp film from the BSi master, while the Ormocomp remained attached to the PMMA (a5). Finally, the Ormocomp Mother stamp was coated with an anti-stiction layer.

Samples with structures on a single face were fabricated by pouring Ormocomp on the Mother stamp and placing a PMMA backplate on top. The Ormocomp was again cured with UV light, through the PMMA, as shown in Figs. 1(b1) and 1(b2). Two identical Ormocomp Mother stamps were used to fabricate samples with identical antireflective structures on the front and back face, see Fig. 1(c). A comparison of the structures on a BSi master and the final Ormocomp sample is shown in Figs. 1(d1) and 1(d2).

The silicon masters and the final Ormocomp samples were characterized by SEM top and side view micrographs. The relative scattering properties of the structures were characterized with a dark field optical microscope (Nikon Eclipse L200). The microscope was calibrated with a highly 


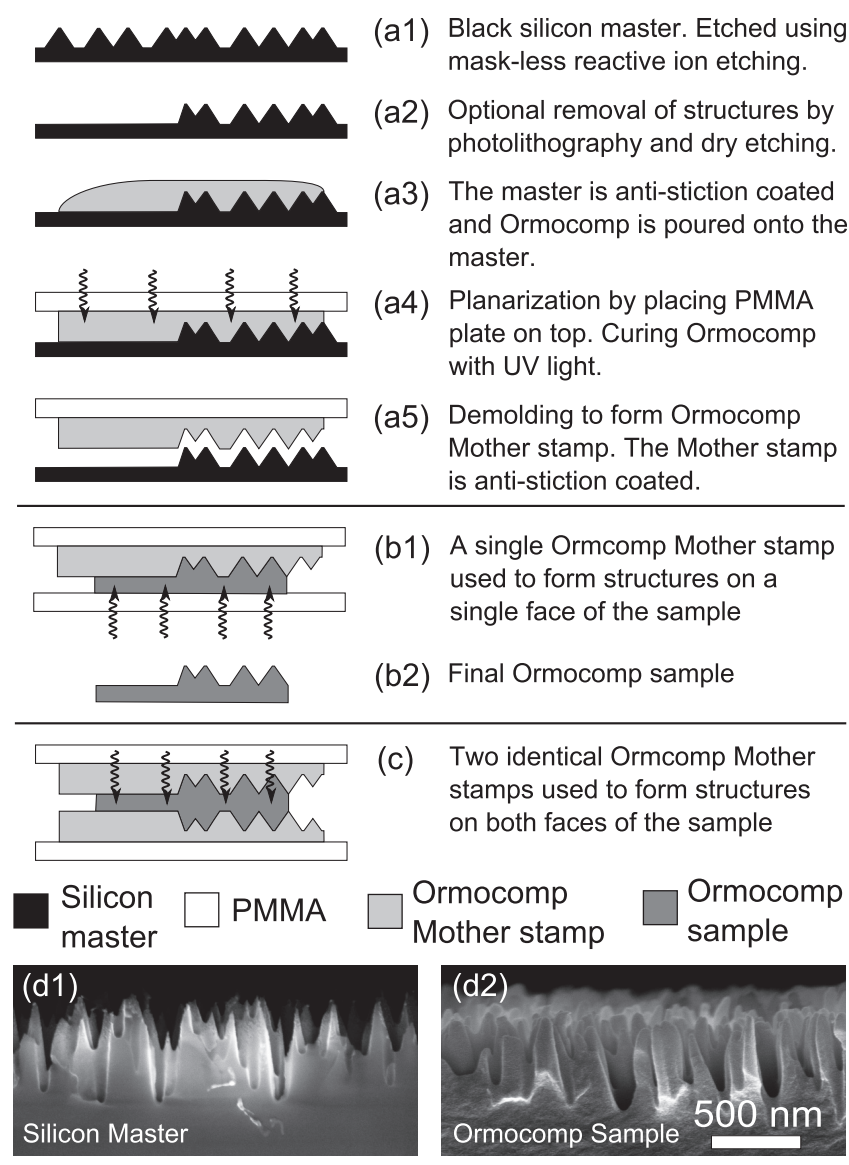

FIG. 1. (a) Process for fabricating Ormocomp Mother stamps. A black silicon master is formed by mask-less reactive ion etching. Selected areas can be removed using conventional photolithography and dry etching. The master is anti-stiction coated and Ormocomp is poured onto the master. A PMMA plate is placed on top, planarizing the Ormocomp film. The Ormocomp is cured with UV light and the Mother stamp is released. (b) The final Ormocomp sample is formed from the Mother stamp similar to steps (a3) and (a4). (c) Using two identical Mother stamps, a sample can be formed with identical nanostructures on each face. (d1) Side view SEM of a black silicon master. (d2) The final Ormocomp sample which was replicated from the Mother stamp.

scattering sample (type F, see Fig. 2), and the exposure settings and white balance were fixed for all recorded images. Thus, the relative scattering properties of the six types of surfaces can be characterized.

Power spectral densities of each Ormocomp sample were calculated from the top view SEM images by azimuthal averaging of the $2 \mathrm{D}$ Fourier spectrum of the surface. ${ }^{12}$ This allows for identifying the dominating spatial frequency of the randomly ordered structures.
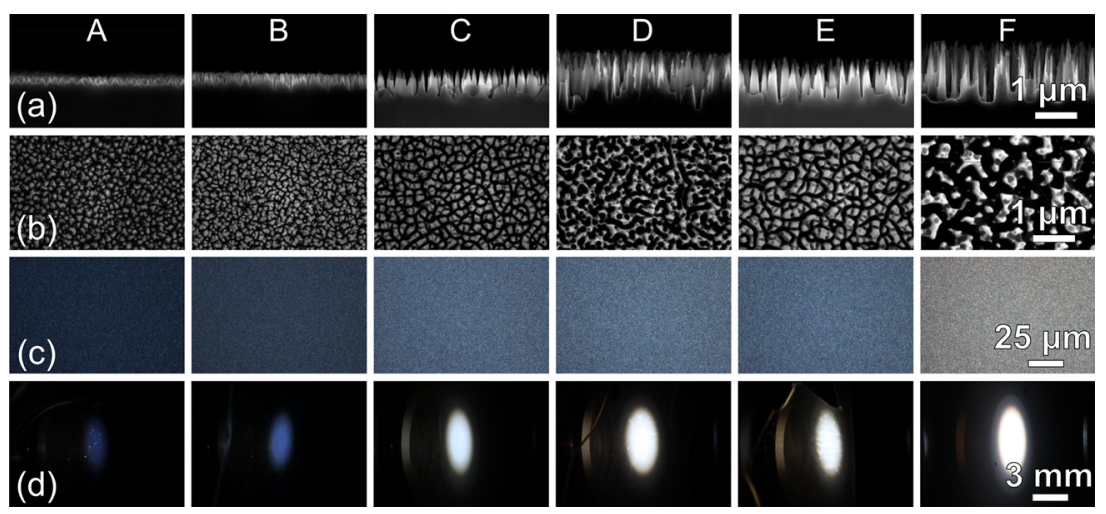

FIG. 2. (a) Side view SEM of BSi. (b) Top view SEM image of BSi. (c) Dark field optical micrographs of BSi. (d) Photographs of fabricated Ormocomp samples. Samples were illuminated by a powerful white light source under normal incidence, and the scattered light was photographed at an oblique angle. (Xenon lamp, HPX-2000, Ocean optics), through a fiber and a collimator. The samples were aligned perpendicular to the incident light using a goniometer. The light was then collected in a fiber with a collimator and analyzed in a spectrometer (Jaz, Ocean Optics). Thus, only non-scattered, directly transmitted light was collected by the collimator.

Angle resolved scattering (ARS) measurements were performed using the same setup, by rotating the collecting fiber around the axis of the illuminated sample. The scattered transmitted light was collected at an angle $(\theta)$ from the normal, in the range $15^{\circ}$ to $90^{\circ}$.

Figures 2(a) and 2(b) show SEM images of the BSi masters as viewed from the side and top, respectively. Fig. 2(c) shows dark field microscope images of the BSi masters. Fig. 2(d) shows photographs of the fabricated Ormocomp samples, when illuminated by an intense white light source (Xenon lamp). The samples were illuminated at normal incidence and photographed from an oblique angle. The results shown in Figs. 2(c) and 2(d) offer a simple comparison of the relative scattering properties of the different BSi masters and the final Ormocomp samples, respectively.

Figure 3(a1) shows the intensity of transmitted, scattered light, measured at an angle of $\theta=30^{\circ}$, for the six different Ormocomp samples. The intensity of the scattered light varies within two orders of magnitude when comparing the different samples. The results show that for all samples, the shorter wavelengths are scattered significantly stronger than the longer wavelengths. Figs. 3(a2) and 3(a3) show surface plots of the full ARS measurements of samples $\mathrm{C}$ and A, respectively.

Figure 3(b) shows the power spectral density of a top view SEM image of a type A Ormocomp sample. The black lines show a fit to a power function of the first and last parts of the data. The intersection of the two lines thus marks the dominating spatial frequency, $q$, of the surface structures, and the error bars represent a $95 \%$ confidence interval on $q$, based on the uncertainties of the parameters of the two fitted functions. Power spectra for the other Ormocomp samples were analyzed in a similar manner, and the intersections are denoted by squares.

Figure 3(c) shows direct transmission measurements of planar and structured Ormocomp samples. For clarity, sample $\mathrm{F}$ is not shown as the transmission is below 0.5 throughout the spectrum. Most samples show antireflective properties at a wavelength of $900 \mathrm{~nm}$, while only sample A 

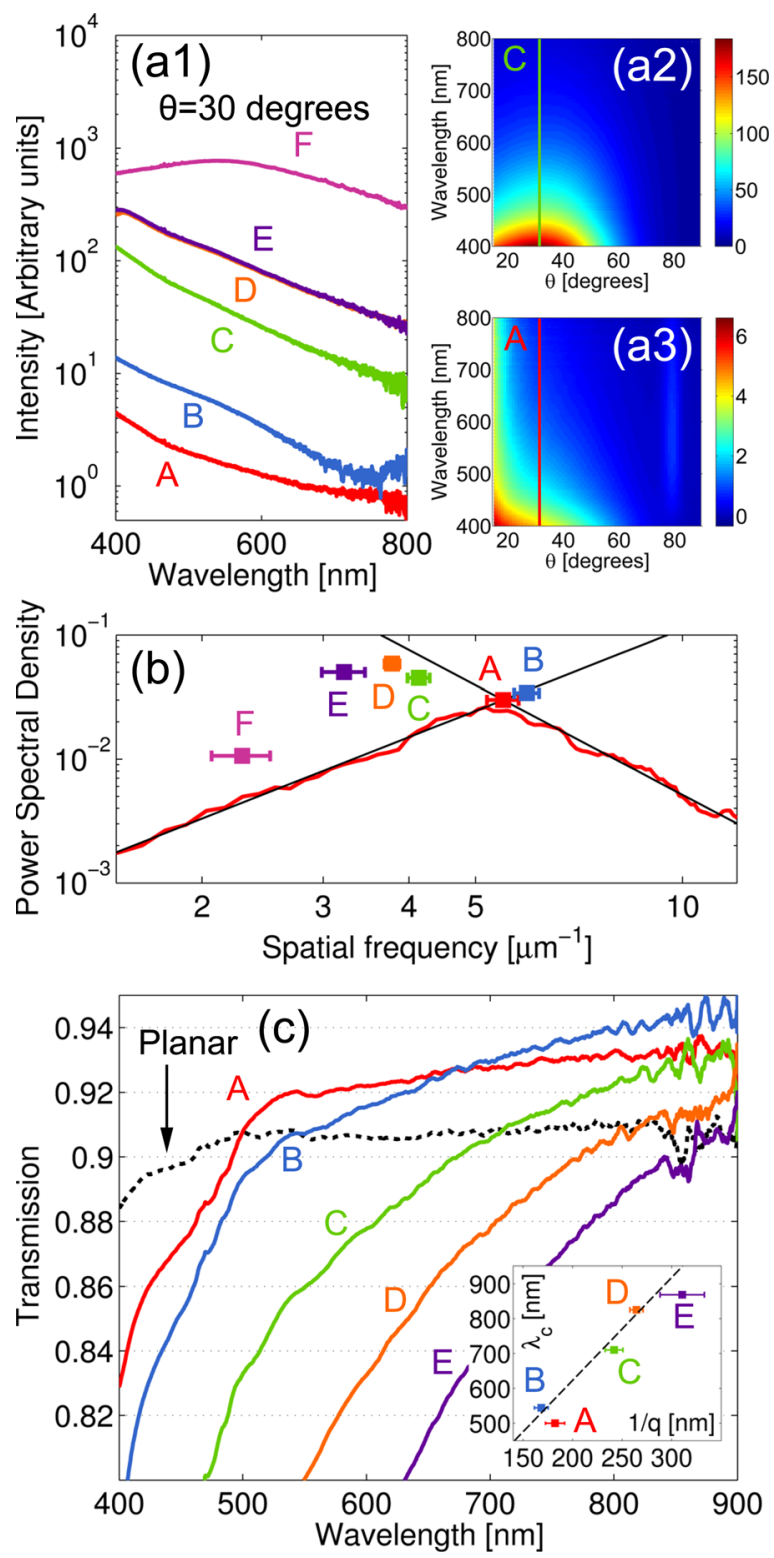

FIG. 3. (a1) Intensity of transmitted, scattered light, measured at an angle of $\theta=30^{\circ}$, for the six different Ormocomp samples. (a2) and (a3) Surface plots of the full ARS measurements of samples $\mathrm{C}$ and A, respectively. (b) Power spectral density of type A Ormocomp sample. The square marked A is the dominating spatial frequency, $q$, found by fitting, with a $95 \%$ confidence interval. Squares marked B-F indicate $q$ for other types of surfaces. (c) Direct transmission measurements of Ormocomp samples with antireflective structures on one face. Inset: Wavelength at intersection between transmission spectra of planar and structured surfaces, $\lambda_{c}$, as a function of the dominating structural periods, $q^{-1}$.

and $\mathrm{B}$ show increased transmission down to $500 \mathrm{~nm}$ and $550 \mathrm{~nm}$, respectively. Samples C, D, and E show reduced transmission in the entire visible spectrum due to scattering. It is evident that the structures of type A, with aspect ratio of 1.3 and height of $200 \mathrm{~nm}$, reduce the reflectance by a factor of 2 , from $4 \%$ and down to $2 \%$ in the visible spectrum.

The inset in Fig. 3(c) shows the wavelength of the intersection of each transmission line with the planar line, denoted $\lambda_{c}$, as a function of the dominating structural periods, $q^{-1}$, found in Fig. 3(b). The plot thus correlates the spatial frequency of the surface structures to the scattering properties. This central result shows that larger values of $q$ lower the cutoff wavelength, $\lambda_{c}$, at which scattering becomes significant.

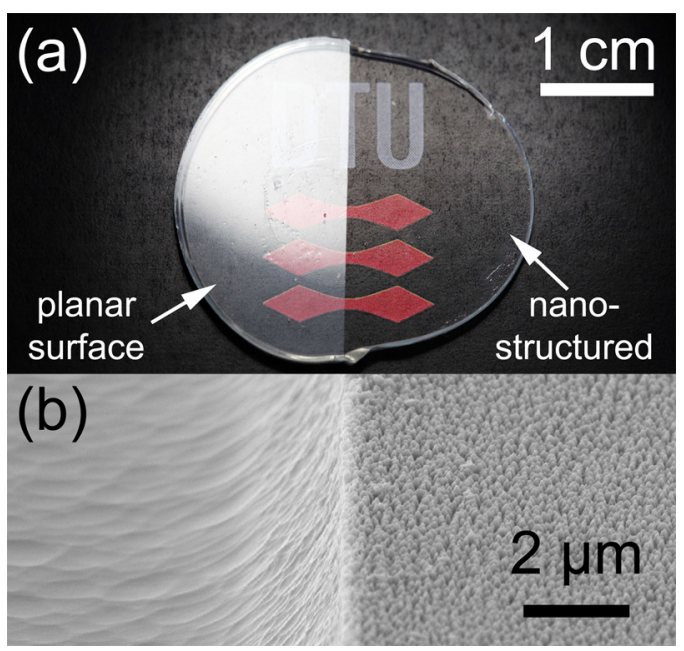

FIG. 4. (a) Photograph of Ormocomp sample with antireflective nanostructures on top and bottom face, placed on a sheet of paper with a printed logo. Nanostructures are on the right side of the fully transparent sample. (b) SEM image of the sample, showing the difference between the planar (left) and the nanostructured surface (right).

This shows that replica of BSi structures are viable for increasing transmission of light in the visible spectrum, despite the random nature on the structures. Furthermore, the scattering properties can be estimated simply from a top view SEM image.

Finally, the type A structures were used to fabricate a sample with nanostructures on both faces, see Fig. 1(c). The resulting sample is shown in Fig. 4(a), where the transparent Ormocomp disc is placed on a sheet of paper with a printed logo. On the left side, the light from a lamp is reflected specularly from the planar top and bottom surface of the sample. On the right side, nanostructures covering both the top and the bottom faces suppress part of the Fresnel reflections, rendering the underlying surface visible. We note that the scattered blue light is too dim to see in daylight conditions.

In conclusion, we have shown that the spatial frequencies of BSi structures are related to the scattering properties of the antireflective surfaces. Structures with a dominating spatial frequency of $160 \mathrm{~nm}$, a height of $200 \mathrm{~nm}$, and aspect ratio of 1.3 show insignificant scattering of light with wavelengths above $500 \mathrm{~nm}$ and reduce Fresnel reflections by up to a factor of 2 . Using a simple two-step casting process, the structures can be fabricated in Ormocomp on areas of up to 3 in. in diameter.

We thank Ole Sigmund, Johannes Weirich, and Jakob Birkedal Wagner for fruitful discussions. The work was supported by the NanoPlast project funded by the Danish National Advanced Technology Foundation (File No. 0072010-2).

${ }^{1}$ H. K. Raut, V. A. Ganesh, A. S. Nair, and S. Ramakrishna, Energy Environ. Sci. 4, 3779 (2011).

${ }^{2}$ K.-C. Park, H. J. Choi, C.-H. Chang, R. E. Cohen, G. H. McKinley, and G. Barbastathis, ACS Nano 6, 3789 (2012).

${ }^{3}$ H. Deniz, T. Khudiyev, F. Buyukserin, and M. Bayindir, Appl. Phys. Lett. 99, 183107 (2011).

${ }^{4}$ E. B. Grann, M. G. Moharam, and D. A. Pommet, J. Opt. Soc. Am. A 11, 2695 (1994).

${ }^{5}$ H. S. Jang, J. H. Kim, K. S. Kim, G. Y. Jung, J. J. Lee, and G. H. Kim, J. Nanosci. Nanotechnol. 11, 291 (2011). 
${ }^{6}$ D. Lehr, M. Helgert, M. Sundermann, C. Morhard, C. Pacholski, J. P. Spatz, and R. Brunner, Opt. Express 18, 23878 (2010).

${ }^{7}$ G. Kumaravelu, M. Alkaisi, and A. Bittar, in Photovoltaic Specialists Conference, 2002. Conference Record of the Twenty-Ninth IEEE (2002), pp. 258-261.

${ }^{8}$ L. Sainiemi, V. Jokinen, A. Shah, M. Shpak, S. Aura, P. Suvanto, and S. Franssila, Adv. Mater. 23, 1 (2011).
${ }^{9}$ C.-C. Hong, P. Huang, and J. Shieh, Macromolecules 43, 7722 (2010).

${ }^{10}$ C.-J. Ting, M.-C. Huang, H.-Y. Tsai, C.-P. Chou, and C.-C. Fu, Nanotechnology 19, 205301 (2008).

${ }^{11}$ J. Clausen, A. B. Christiansen, J. Garnaes, N. A. Mortensen, and A. Kristensen, Opt. Express 20, 4376 (2012).

${ }^{12}$ S. Schroeder, A. Duparre, L. Coriand, A. Tuennermann, D. H. Penalver, and J. E. Harvey, Opt. Express 19, 9820 (2011). 